\title{
Molecular Phylogeny of the Marmots (Rodentia: Sciuridae): Tests of Evolutionary and Biogeographic Hypotheses
}

\author{
Scott J. Steppan, 1,2,5 Mikhail R. AkhVerdyan, 3,4 Elena A. Lyapunova, ${ }^{3}$ \\ Darrilyn G. Fraser, 1,6 Nikolai N. Vorontsov, ${ }^{3}$ Robert S. HofFmanN, ${ }^{2}$ \\ AND MICHAEL J. BRAUN ${ }^{1,2}$ \\ ${ }^{1}$ Laboratory of Molecular Systematics, Smithsonian Institution, 4210 Silver Hill Road, \\ Suitland, Maryland 20746, USA; E-mail: steppan@bio.fsu.edu (S.J.S.) \\ ${ }^{2}$ Department of Vertebrate Zoology, National Museum of Natural History, Smithsonian Institution, \\ Washington, DC 20560, USA \\ ${ }^{3}$ Institute of Developmental Biology, Russian Academy of Sciences, Moscow, Russia \\ ${ }^{4}$ Institute of Zoology, National Academy of Sciences, Republic of Armenia, 375014 Yerevan, Armenia
}

\begin{abstract}
There are 14 species of marmots distributed across the Holarctic, and despite extensive systematic study, their phylogenetic relationships remain largely unresolved. In particular, comprehensive studies have been lacking. A well-supported phylogeny is needed to place the numerous ecological and behavioral studies on marmots in an evolutionary context. To address this situation, we obtained complete cytochrome (cyt) $b$ sequences for 13 of the species and a partial sequence for the 14th. We applied a statistical approach to both phylogeny estimation and hypothesis testing, using parsimony and maximum likelihood-based methods. We conducted statistical tests on a suite of previously proposed hypotheses of phylogenetic relationships and biogeographic histories. The cyt $b$ data strongly support the monophyly of Marmota and a western montane clade in the Nearctic. Although some other scenarios cannot be rejected, the results are consistent with an initial diversification in North America, followed by an invasion and subsequent rapid diversification in the Palearctic. These analyses reject the two major competing hypotheses of M. broweri's phylogenetic relationships-namely, that it is the sister species to M. camtschatica of eastern Siberia, and that it is related closely to M. caligata of the Nearctic. The Alaskan distribution of M. broweri is best explained as a reinvasion from the Palearctic, but a Nearctic origin can not be rejected. Several other conventionally recognized species groups can also be rejected. Social evolution has been homoplastic, with large colonial systems evolving in two groups convergently. The cyt $b$ data do not provide unambiguous resolution of several basal nodes in the Palearctic radiation, leaving some aspects of pelage and karyotypic evolution equivocal. \{Beringia; cytochrome $b$; Holarctic; hypothesis testing; Marmota; phylogenetics.\}
\end{abstract}

There is a growing movement in systematics from simply making estimates of phylogeny to hypothesis testing and reliability estimation (Huelsenbeck and Rannala, 1997). This statistical perspective allows more precise delineation of which relationships are well understood and which need additional investigation. It also promotes the generation of explicit evolutionary and biogeographic models while providing the tools to reject hypotheses. These developments promise to accelerate our understanding of evolution by improving our hy-

5Present address (and address for correspondence): Department of Biological Science, Florida State University, Tallahassee, Florida 32306-1100, USA; E-mail: steppan@bio.fsu.edu

${ }^{6}$ Present address: Department of Veterinary Microbiology and Pathology, Washington State University, Pullman, Washington 40456, USA potheses, defining well-resolved nodes of the phylogeny, and identifying unresolved relationships, thereby focusing our efforts more efficiently.

Here, we employ a statistical approach, using both parsimony and likelihood analyses of molecular sequence data to test a suite of previously proposed hypotheses of phylogenetic relationships in marmots (Marmota). A sequential phylogenetic estimation procedure was used that culminated in a maximum likelihood analysis utilizing a model of sequence evolution with parameters estimated from the data.

Marmots are large terrestrial rodents found today throughout much of northern Eurasia and North America, including the Bering Strait region of western Alaska and eastern Siberia (Fig. 1). Their ecology and ethology has been studied extensively (e.g., 
Armitage, 1975, 1987; Barash, 1989; Arnold, 1990; Blumstein et al., 1997) and thus, along with their close relatives the ground squirrels and prairie dogs, marmots have figured prominently in general theories of mammalian social evolution. Social systems vary widely in marmots, from the solitary monax to the large, almost prairie dog-like colonies of bobak, sibirica, and himalyana. Moreover, the phylogenetic relationships, derived from morphological and karyological data, between marmots and related ground squirrels are poorly known and controversial (Black, 1963; Gromov et al., 1965; Hafner, 1984), as are relationships within the genus (Hoffman and Nadler, 1968; Vorontsov et al., 1969; Bibikov, 1996). There are no well-supported and corroborated phylogenetic hypotheses within the genus. Explicit models of marmot social evolution have been proposed (Barash, 1989) but they cannot be tested without a robust phylogeny.

Marmots also provide biogeographic insights to an important but still insuffi- ciently well understood faunal interchange across the Bering land bridge (Beringia). During the Plio-Pleistocene period of the last several million years, this region was an important connection between the two hemispheres during periods of glacial maxima, when the Bering land bridge was in existence. During interglacial times, however, this region has been a water barrier to the movement of terrestrial mammals, the rising sea level flooding the land bridge to form the Bering Strait (Hopkins et al., 1982; Hoffmann, 1984). Fossil evidence suggests that marmots first arose in North America (Black, 1963). Their spread into Eurasia would likely have occurred across Beringia, but the timing of this event is only loosely constrained by currently available fossil evidence (Gromov et al., 1965; Savage and Russell, 1983). The Alaskan species $M$. broweri has been proposed to be a reinvasion of the Nearctic from the Palearctic (Hoffmann et al., 1979), owing to its hypothesized Palearctic affinities, and thus may provide additional information re-

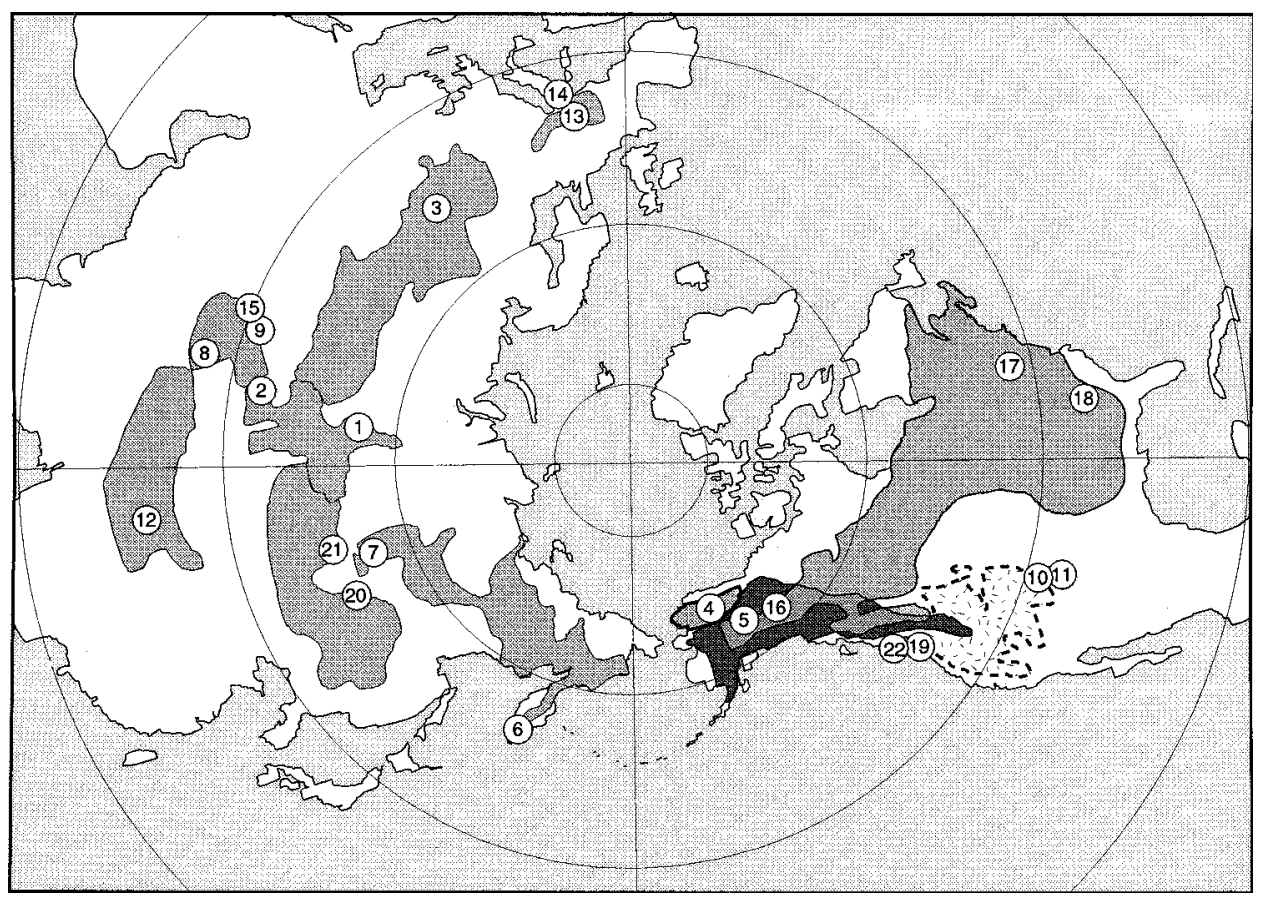

FIGURE 1. Geographic distribution of Marmota species. Numbers indicate collecting localities: $1=$ baibacina 1; $2=$ baibacina $2 ; 3=$ bobak 1 and $2 ; 4=$ brower 1 and $2 ; 5=$ caligata $; 6=$ camtschatica $1 ; 7=$ camtschatica $2 ; 8=$ caudata 1 ; $9=$ caudata 2 and $3 ; 10=$ flaviventris $1 ; 11=$ flaviventris $2 ; 12=$ himalayana $; 13=$ marmota $1 ; 14=$ marmota $2 ; 15=$ menzbieri $; 16=\operatorname{monax} 1 ; 17=\operatorname{monax} 2 ; 18=\operatorname{monax} 3 ; 19=$ olympus $; 20=$ sibirica $1 ; 21=$ sibirica $2 ; 22=$ vancouverensis . 
garding the timing and directionality of the faunal interchanges.

\section{Taxonomic Background}

The taxonomy of the genus Marmota, particularly its Old World members, has until recently been unstable. Ellerman and Morrison-Scott (1951) recognized only three widely ranging species of this genus in the Palearctic, M. bobak (incl. himalayana and sibirica), M. caudata, and M. marmota (including camtschatica, baibacina, and menzbieri). Rausch (1953) extended their polytypic species concept of M. marmota to also include M. caligata (incl. M. broweri, olympus, and vancouverensis). In contrast, Hall and Kelson (1959) placed caligata (incl. M. broweri), olympus, and vancouverensis at the species level, as well as flaviventris and monax, which had been universally regarded as distinct species. Thus, in the 1950s, at the height of popularity of the "biological species concept" (Huxley, 1940), only five or six species of Holarctic marmots were accepted by many systematists.

The following decades, which saw the widespread application of karyological data to systematic questions, resulted in a turnabout. In the Palearctic, eight taxa were considered full species, and in the Nearctic, six, for an Holarctic total of 14 (Gromov et al., 1965; Rausch and Rausch, 1965; Hoffmann and Nadler, 1968; Vorontsov et al., 1969; Vorontsov and Lyapunova, 1970; Rausch and Rausch, 1971). Their status remains the same at present (Hoffmann et al., 1993).

The first attempt to assess relationships among species of marmots was that of Howell (1915), who defined three species groups of Nearctic marmots, the caligata group (also including olympus and vancouverensis), the flaviventris group, and the monax group; Howell also pointed out similarities between the latter and the Palearctic M. marmota. Ognev (1947) suggested affiliation of bobak, himalayana, baibacina, and sibirica, and possibly, camtschatica and caligata in one group; he believed marmota, caudata, and menzbieri each to be separate groups. Gromov et al. (1965) modified Ognev's groupings; their bobak group included baibacina, himalayana, sibirica, and camtschat- $i c a$, these latter linking the bobak group with marmota, which they affiliated with monax. They also considered the Alaskan broweri as a representative of the Asiatic marmots in the Nearctic, while recognizing the caligata group (including olympus and vancouverensis) as close to the marmota group. Finally, Lyapunova et al. (1992) considered camtschatica a member of the American, rather than the Asian, group of marmots.

The first comprehensive hypothesis of the origin and evolution of the genus Marmota in the Holarctic was published by Hoffmann and Nadler (1968). On the basis of both morphological and chromosomal characters as well as the fossil record, marmots were at that time supposed to have evolved from ground squirrels in North America in the early Pliocene. Radiating from there, a species that probably resembled monax and marmota migrated into Eurasia across the Bering land bridge in the late Pliocene, and reached western Eurasia by the Pleistocene. A radiation in North America gave rise to the monax, flaviventris, and caligata groups, while a Eurasian radiation produced marmota and the Asiatic marmots (bobak group, menzbieri, and caudata), plus broweri, which migrated back across the Bering land bridge in the late Pleistocene to northern Alaska. $M$. broweri thus represented the Asiatic camtschatica (of the bobak group) in the Nearctic (Hoffmann et al., 1979).

All Palearctic species excluding marmota possess black-tipped guard hairs, which are softer and finer than the guard hairs in the rest of the genus and has led to those Palearctic species being heavily exploited for their fur. The greater insulation provided by fine, dense hair has been suggested to be advantageous to marmots spreading across the Palearctic during the Pleistocene, when the climate was rapidly cooling in Siberia. According to Zimina and Gerasimov (1973:335), “. . . modern habitats of M. baibacina and M. camtschatica may be similar to the conditions under which marmots lived in the periglacial zone ... \{being\} better adapted to periglacial conditions ..." If this scenario is correct, blacktipped guard hairs would represent one of the few explicit morphological synapomorphies and biogeographically significant adaptations. 


\section{A Priori Hypotheses}

Many biogeographic and evolutionary models make predictions about phylogenetic relationships; they can therefore be translated into phylogenetic trees, which can then be evaluated using statistical tests (Fig. 2). We tested a series of hypotheses that either represented strongly argued hypotheses from the systematic literature or were particularly important to the biogeography or social and chromosomal evolution of marmots. The phylogenetically explicit hypotheses tested herein are: 1) Marmota is not monophyletic; 2) broweri and camtschatica are sister species (Hoffmann et al., 1979); 3) broweri and caligata are conspecific or sister species (Rausch and Rausch, 1971; Hall, 1981). Hypotheses 2 and 3 imply dichotomous biogeographic scenarios, involving either a dispersal or vicariant event across the Bering land bridge (hypothesis 2) or simple local differentiation (hypothesis 3 ). The following biogeographic and evolutionary scenarios were also evaluated (with phylogenetic hypotheses): 4) There was a single crossing of Beringia (Palearctic species monophyletic; the most-parsimonious biogeographic scenario); 5) original diversification was in North America (North American species basal and paraphyletic; paleontological hypothesis); 6) black-tipped hairs evolved once without reversal (monophyly of all Asian species excluding marmota; proposed morphological synapomorphy); 7) increased sociality to large colonies evolved once without reversal (monophyly of bobak, sibirica, himalayana; most-parsimonious ethological scenario); 8) there has been minimum karyotypic evolution among Nearctic species, consistent with the transformation series $2 n=38$ (most marmots) $\rightarrow 40$ (olympus) $\rightarrow 42$ (caligata, flaviventris, vancouverensis).

\section{METHODS \\ Specimens Examined}

Twenty-five specimens representing all 14 currently recognized species in the genus

\section{2.}

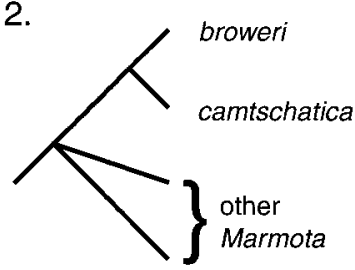

4.

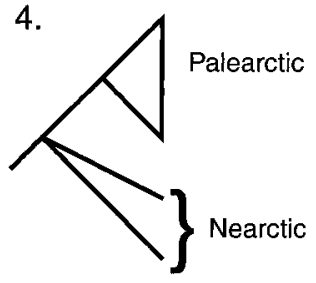

7.

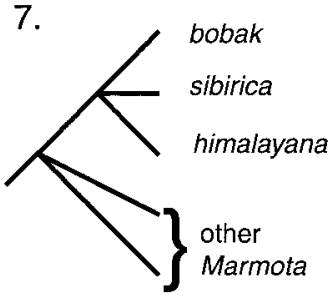

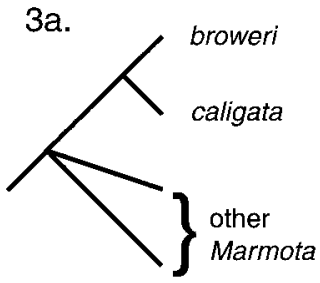
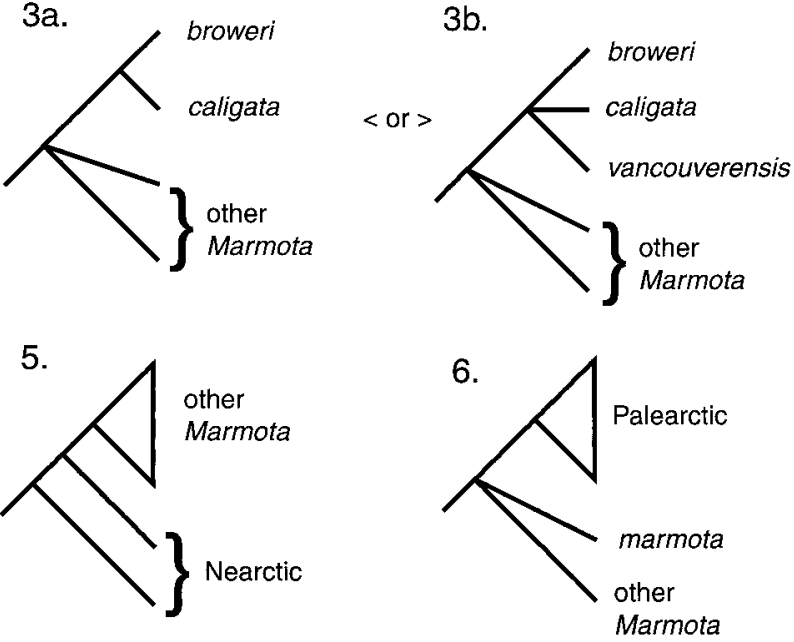

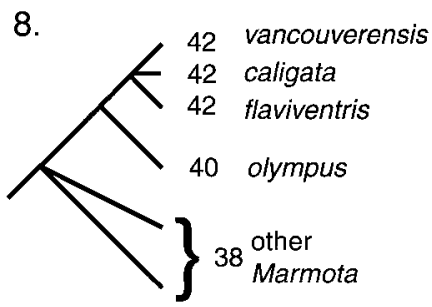

FIGURE 2. Model cladograms representing a priori hypotheses presented in the text. Hypothesis 1, Marmota monophyly, is not shown. Numbers on hypothesis 8 represent chromosome numbers. 
Marmota (Hoffmann et al., 1993) were sequenced for this study. Five species are represented by one specimen, and the remaining nine by two or more specimens, usually from different localities and assignable to named subspecies (see Appendix). The endangered species vancouverensis was imported under USFWS permit no. PRT802845. Additional taxa included in the analyses as outgroups were five published ground and tree squirrel sequences-Sciurus carolinensis, Spermophilus (Spermophilus) columbianus, S. (S.) richardsoni, S. (Callospermophilus) lateralis, and S. (Ictidomys) tridecemlineatus (Thomas and Martin, 1993)—and four unpublished ground squirrel sequences supplied by R. Harrison and P. Sherman: $S$. (Otospermophilus) beecheyi, S. (S.) fulvus, S. saturatus, and $S$. (S.) undulatus. Sequences have been submitted to Genbank and assigned accession numbers AF14314-39.

\section{DNA Extraction, Amplification, and Sequencing}

Total genomic DNA was extracted from frozen liver or blood of 24 individuals (all but olympus) by following standard phenol/ chloroform extraction techniques (Sambrook et al., 1989). The entire cytochrome (cyt) $b$ gene was amplified from the mitochondrial genome via polymerase chain reaction (PCR) using primers L14725 (P484; TGAAAAAYCATCGTTGT) and H15915 (P485; TYTYCWTYTTNGGTTTACAARAC) modified from the universal mammalian primers of Irwin et al. (1991). L and H refer to the light and heavy strands, respectively, and the numbers following them refer to the position of the 3 ' base of the primers in relation to human mtDNA (Anderson et al., 1981). P numbers refer to specific primer batches in use at the Laboratory of Molecular Systematics, Smithsonian Institution. Amplifications were performed in 50-100 $\mu 1$ total reaction volumes containing $1.5-3.0$ $\mathrm{mM} \mathrm{MgCl}, 1.0 \mu \mathrm{M}$ of each primer, $5.0 \mathrm{U}$ of Taq DNA polymerase or Amplitaq Gold (Perkin-Elmer-Cetus or Promega, respectively) in a buffer supplied by the respective enzyme manufacturer. Typical cycling conditions were initial denaturation at $94-95^{\circ} \mathrm{C}$ for $3 \mathrm{~min} 45 \mathrm{~s}(17 \mathrm{~min}$ for Amplitaq Gold), followed by 25 to 30 cycles of denat- uration $\left(1 \mathrm{~min}\right.$ at $\left.94-95^{\circ} \mathrm{C}\right)$, primer annealing $\left(1 \mathrm{~min}\right.$ at $\left.52-55^{\circ} \mathrm{C}\right)$, and DNA extension $\left(2 \mathrm{~min}\right.$ at $\left.72^{\circ} \mathrm{C}\right)$. A final extension for $7 \mathrm{~min}$ at $72^{\circ} \mathrm{C}$ was included to minimize the number of partial strands. Five microliters of the double-stranded product was electrophoresed on a $1 \%$ agarose gel, stained with ethidium bromide, and visualized under UV to assess reaction success. The products were then cleaned by filtration through Ultrafree-MC 100,000 NMWL filters (Millipore Corp., Bedford, MA) or by precipitation with polyethylene glycol (PEG) in saline $(\mathrm{NaCl})$ and resuspended in $25 \mu$ of purified $\mathrm{H}_{2} \mathrm{O}$. One to two microliters of the cleaned PCR product was electrophoresed again to estimate concentration visually by comparison with size standards.

For initial sequencing of the doublestranded templates, we used T7 DNA polymerase in the Sequenase 2.0 kit (United States Biochemical, Cleveland, $\mathrm{OH}$ ), following the manufacturer's protocols. The products of the sequencing reaction were resolved in $6 \%$ polyacrylamide gels, which were autoradiographed for 5 to 10 days at room temperature and read manually. The initial sequences were confirmed and extended by automated sequencing of the full-length amplicons with use of 26 to 40 ng of double-stranded template and ABI Prism dye terminator sequencing chemistry on ABI 373A (Perkin-Elmer) automated sequencers. All 24 individuals were sequenced completely in both directions for the entire cyt $b$ gene by using the amplication primers and the following sequencing primers: P499 (L14994: 5'-TGACTTATCCG CTATATACA-3'), P1185 (L15279: 5'-AA AGCYACYYTAACACGATT-3'), L15615 (5'ATTCTTAACAAACTAGGAGG-3'), P1188 (L15615: 5'-ATCCCCAACAAATTAGGAG G-3'), P1189 (H15756: 5'-CRGGYTGTCCT CCRATTC-3'), P500 (H15481: 5'-CTCCTA GAAGGTCAGGTGAA-3'), P386 (H15149: 5'-TTTCTGCAGCCCCTCAGAATGATATT TGTCCTCA-3'), P1190 (H14993: 5'-ATTATT GATGCACCGTTRGCATG-3'). Additional primers were used for manual sequencing: P442 (L14841: 5'-AAGCTTCCATCCAAC A-3'), P586 (L15171: 5'-CAAATKTCATTYT GAGGNGCAAC-3'), P509 (L15350: 5'-GK TTKTTIGAICCIGTYTC-3'), P443 (H15498: 5'-CTGCAGGGAATAAAGT-3'). 
Because no frozen tissue was available for olympus, dried tissue adhering to a cleaned museum skull was collected from a specimen prepared in 1927. DNA was extracted from $\sim 2 \mathrm{mg}$ of dry tissue by grinding in liquid nitrogen, adding $100 \mu 1$ of Chelex to the ground tissue, and incubating at $98^{\circ} \mathrm{C}$ for $10 \mathrm{~min}$. Three pieces of tissue were processed and extraction-negative controls were prepared for each. All extractions were conducted in a laboratory that has never been exposed to PCR products.

For olympus, standard PCR procedures were used except that experiments were run on the three extraction-positive and three extraction-negative samples in addition to the PCR-positive and PCR-negative controls used throughout. Nine primer pair combinations with amplicon sizes ranging from 113 to $308 \mathrm{bp}$ were used. For those primer pairs that resulted in products, all three extractions showed product in repeated experiments, whereas negatives usually showed none. In the two cases where a faint band was visible in a negative control (both involving the same primer pairs), the product was purified and sequenced for comparison. A BLAST search in GenBank on the potential contaminants returned human cyt $b$ as the closest matches for both, which were otherwise $>20 \%$ divergent from the probable olympus products produced during the same experiments. These olympus products were $<6.5 \%$ divergent in sequence- but not identical to-the other Nearctic species to which olympus was expected to be most closely related. Sequencing of olympus PCR products was as specified above except that a total of $577 \mathrm{bp}$ nucleotides were determined (on both strands).

\section{Phylogeny Estimation}

Sequences were aligned by using Sequencher 3.0 (Gene Codes Corp.). Alignments were unambiguous because insertions and deletions were absent and protein structure was sufficiently conserved. Pairwise genetic distances (e.g., absolute and maximum likelihood) were calculated and all phylogenetic analyses were conducted by using a beta test version of PAUP* 4.0d61a (D. Swofford, pers. comm.) Trees were rooted by using Sciurus. Examination of preliminary results indicated that the region between 700 and $900 \mathrm{bp}$ downstream from the start codon of a published flaviventris sequence (Thomas and Martin, 1993) was highly divergent from all other taxa, including $16.7 \%$ Kimura two-parameter (K2P distance; Kimura, 1980) from our flaviventris over this region. Analyzing this 200-bp region separately from the rest of the gene produced cladograms in which the published flaviventris was a divergent branch outside the Marmota clade. All wellsupported relationships among other taxa from the analyses on all the data were otherwise recovered from this fragment. We also sequenced two other flaviventris that were $2.5 \%$ divergent over this region. Given the uncertainty regarding that published sequence, we did not include it in the analyses.

Phylogenetic analyses were conducted by using distance (neighbor joining; NJ), maximum parsimony (equally weighted, MP; weighted parsimony, WP), and maximum likelihood (ML) criteria. A sequential optimization approach (Fratti et al., 1997) was used to estimate the phylogeny. Initial trees were generated by NJ with use of multiple distance measures and by MP with all characters weighted equally. The distance metric used in NJ had no effect on topology. Transversion/transition ratios ( $\mathrm{tv} / \mathrm{ts})$ and relative variability for first, second, and third codon positions were estimated by using ML with a K2P model on the MP tree. WP analyses were then conducted with character weights for transversions and codon position based on the inverse of the estimated evolutionary rates $(\mathrm{tv} / \mathrm{ts}=7: 1$, $7: 1,12: 1$ for the three codon positions respectively, and positions were weighted 1st:2nd:3rd = 5:12:1). All MP and WP analyses used heuristic searches with tree bisection-reconnection (TBR) branch-swapping and 30 random addition replicates. ML parameter values were estimated under a nested array of substitution models for each of these three trees: NJ, MP, and WP (Fratti et al., 1997). These models were Jukes-Cantor (JC: Jukes and Cantor, 1969), K2P (Kimura, 1980), HKY85 (Hasegawa et al., 1985), and general time reversible (GTR). Each of these models was adjusted for among-site rate variation in four ways: 
All sites were assumed to have equal rates, a portion of the sites was assumed to be invariable (I), rates among all sites were assumed to vary following a gamma distribution $(\Gamma$ : Yang, 1994), and a combination of invariable sites and gamma-distributed rates was used. The combination of four substitution and four rate-distribution models resulted in each tree being evaluated for 16 models. Estimated parameter values differed by $<3 \%$ among the three starting topologies within each model.

Because each of the models can be considered a special case of the most general GTR + I + $\Gamma$, a likelihood-ratio test can be used to test for significant differences in the fits of the models (Yang et al., 1995), with the degrees of freedom being equal to the difference in the number of parameters. The GTR $+I+\Gamma$ model was a significantly better fit for each of the trees. A ML search was then conducted by using the GTR $+\mathrm{I}+\Gamma$ model with parameters fixed to the values estimated on all three initial trees. Heuristic searches were conducted with 20 random addition replicates and TBR branch-swapping. All three searches yielded the same single topology. A final ML analysis utilizing the same search conditions was conducted by using the parameters estimated from the topology produced by the first three ML searches.

\section{RoBUSTNESS AND Hypothesis TESTING}

Robustness of the results for each set of analyses (initial NJ, MP, WP, and final ML) was estimated for 100 bootstrap replicates (Felsenstein, 1985). Decay (or Bremer support) indices (Bremer, 1994) were calculated for selected nodes by searching for the shortest trees containing the hypothesized constraint under equal-weighting.

A priori hypotheses were tested by using parsimony- and likelihood-based approaches. Equally weighted MP searches were conducted with constraints enforced to match predicted topologies for each hypothesis. Differences in tree lengths between constrained searches and the mostparsimonious tree were tested by using the Kishino-Hasegawa (Kishino and Hasegawa, 1989) and Templeton (Templeton, 1987) tests. Because the topology of the ref-
TABlE 1. Nucleotide composition averaged over the sciurid species examined in this study.

\begin{tabular}{lcccc}
\hline Codon position & A & C & G & T \\
\hline First & 0.292 & 0.245 & 0.211 & 0.253 \\
Second & 0.199 & 0.238 & 0.140 & 0.423 \\
Third & 0.375 & 0.296 & 0.027 & 0.303 \\
Total & 0.289 & 0.260 & 0.126 & 0.326 \\
\hline
\end{tabular}

erence (optimal) tree was not defined a priori, we applied one-tailed tests at the $2.5 \%$ significance level as a conservative test. The same approach was employed with ML by using the optimal ML tree as the reference.

\section{RESULTS}

Each Marmota sequence has an open reading frame of $1140 \mathrm{bp}$. There were 507 variable sites, 399 of which were parsimony-informative. Only $25 \%$ of the variable sites involve nonsynonymous substitutions. Nucleotide composition is very close to mean mammalian values (Irwin et al., 1991) for first and second positions (Table 1). The sciurids examined in the study (including outgroups) show a higher frequency of Ts at the third position $(0.303$ vs. 0.103-0.221), with correspondingly lower

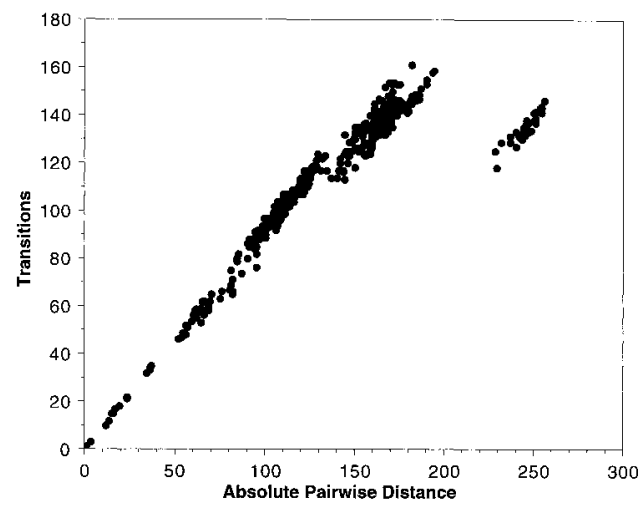

FIGURE 3. Saturation curve for transitions. The pairwise comparisons of absolute number of differences fall into three groups: within genera $(<134$ total distance), between Marmota and Spermophilus (134-200), and between Sciurus and all others ( $>200)$. The comparison between Sciurus and M. olympus is deleted for clarity because the combination of fewer nucleotides in M. olympus and saturation effects makes it appear incorrectly to be an outlier. 
TABLE 2. Distance matrix for all Marmota sequenced. Absolute number of differences above diagonal; maximum likelihood distances using model and parameters $(G T R+I+\Gamma)$ estimated from ML tree below the diagonal.

\begin{tabular}{|c|c|c|c|c|c|c|c|c|c|c|c|}
\hline & 1 & 2 & 3 & 4 & 5 & 6 & 7 & 8 & 9 & 10 & 11 \\
\hline (1) olympus & 0 & 37 & 34 & 36 & 36 & 68 & 66 & 64 & 56 & 56 & 63 \\
\hline (2) flaviventris 1 & 0.083 & 0 & 17 & 66 & 65 & 116 & 117 & 114 & 126 & 123 & 132 \\
\hline (3) flaviventris 2 & 0.073 & 0.016 & 0 & 60 & 61 & 113 & 114 & 113 & 118 & 115 & 127 \\
\hline (4) vancouverensis & 0.080 & 0.072 & 0.063 & 0 & 13 & 106 & 107 & 106 & 119 & 116 & 121 \\
\hline (5) caligata & 0.079 & 0.070 & 0.064 & 0.012 & 0 & 107 & 108 & 107 & 116 & 113 & 123 \\
\hline (6) $\operatorname{monax} 2$ & 0.205 & 0.151 & 0.146 & 0.138 & 0.138 & 0 & 15 & 16 & 109 & 110 & 109 \\
\hline (7) $\operatorname{monax} 3$ & 0.191 & 0.152 & 0.146 & 0.138 & 0.138 & 0.014 & 0 & 19 & 112 & 113 & 114 \\
\hline (8) $\operatorname{monax} 1$ & 0.186 & 0.146 & 0.145 & 0.137 & 0.137 & 0.015 & 0.018 & 0 & 111 & 112 & 107 \\
\hline (9) marmota 1 & 0.149 & 0.166 & 0.151 & 0.156 & 0.150 & 0.140 & 0.143 & 0.141 & 0 & 3 & 115 \\
\hline (10) marmota 2 & 0.149 & 0.161 & 0.146 & 0.151 & 0.144 & 0.142 & 0.145 & 0.144 & 0.003 & 0 & 114 \\
\hline (11) broweri 1 & 0.166 & 0.177 & 0.168 & 0.161 & 0.163 & 0.140 & 0.148 & 0.136 & 0.146 & 0.144 & 0 \\
\hline (12) broweri 2 & 0.171 & 0.179 & 0.170 & 0.164 & 0.166 & 0.142 & 0.150 & 0.138 & 0.148 & 0.146 & $8.8 \mathrm{e}-4$ \\
\hline (13) menzbieri & 0.127 & 0.155 & 0.140 & 0.159 & 0.158 & 0.143 & 0.145 & 0.140 & 0.136 & 0.137 & 0.139 \\
\hline (14) caudata 3 & 0.146 & 0.142 & 0.136 & 0.141 & 0.147 & 0.110 & 0.123 & 0.119 & 0.115 & 0.117 & 0.115 \\
\hline (15) caudata 2 & 0.146 & 0.142 & 0.136 & 0.141 & 0.147 & 0.110 & 0.123 & 0.119 & 0.115 & 0.117 & 0.115 \\
\hline (16) caudata 1 & 0.145 & 0.141 & 0.139 & 0.147 & 0.145 & 0.120 & 0.131 & 0.126 & 0.117 & 0.119 & 0.114 \\
\hline (17) baibacina 2 & 0.151 & 0.142 & 0.131 & 0.131 & 0.131 & 0.124 & 0.114 & 0.123 & 0.138 & 0.137 & 0.132 \\
\hline (18) baibacina 1 & 0.167 & 0.154 & 0.138 & 0.144 & 0.144 & 0.136 & 0.127 & 0.139 & 0.144 & 0.146 & 0.143 \\
\hline (19) bobak 1 & 0.142 & 0.136 & 0.127 & 0.136 & 0.136 & 0.116 & 0.120 & 0.122 & 0.127 & 0.129 & 0.134 \\
\hline (20) bobak 2 & 0.163 & 0.142 & 0.133 & 0.144 & 0.144 & 0.121 & 0.125 & 0.127 & 0.135 & 0.137 & 0.139 \\
\hline (21) himalayana & 0.189 & 0.156 & 0.141 & 0.163 & 0.167 & 0.127 & 0.121 & 0.117 & 0.133 & 0.135 & 0.150 \\
\hline (22) sibirica 2 & 0.168 & 0.151 & 0.140 & 0.163 & 0.167 & 0.134 & 0.127 & 0.130 & 0.131 & 0.133 & 0.131 \\
\hline (23) sibirica 1 & 0.169 & 0.153 & 0.141 & 0.163 & 0.167 & 0.134 & 0.127 & 0.130 & 0.132 & 0.134 & 0.131 \\
\hline (24) camtschatica 2 & 0.136 & 0.171 & 0.158 & 0.171 & 0.168 & 0.155 & 0.146 & 0.148 & 0.135 & 0.137 & 0.160 \\
\hline (25) camtschatica 1 & 0.134 & 0.170 & 0.154 & 0.167 & 0.164 & 0.156 & 0.146 & 0.148 & 0.134 & 0.136 & 0.153 \\
\hline
\end{tabular}

frequencies of A (0.375 vs. $0.363-0.474)$ and C (0.296 vs. 0.329-0.479). There was no significant variation in nucleotide composition among the sciurids. Transitions show no evidence of saturation within Marmota but do appear to be saturated in comparisons between Sciurus and the marmotines (Fig. 3), a pattern commonly observed for mammalian groups with these cyt $b$ divergences. Uncorrected and ML estimates (GTR $+\mathrm{I}+\Gamma$; in parentheses) in divergence are as follows: within species, $0-3.2 \%, \bar{x}=$ $1.27 \%, n=13(0-3.5 \% ; \bar{x}=1.36 \%)$; among Marmota species, $1.1-11.9 \% ; \quad \bar{x}=8.5 \%, n=$ $300(1.2-20.5 \% ; \quad \bar{x}=13.3 \%) ;$ and between Marmota and Spermophilus, $11.8-17.0 \%, \bar{x}=$ $14.7 \%, n=125(19.6-37.2 \% ; \quad \bar{x}=27.6 \%)$ (Table 2). Only one interspecific distance overlaps the range of values observed for intraspecific comparisons: caligata and vancouverensis were $1.2 \%$ distant (Fig. 4). All other interspecific ML distances exceeded $6 \%$. Estimated ts $/ \mathrm{tv}$ ratios (K2P) for each codon position were 7.7, 6.5, and 11 for first, second, and third positions, respectively. The aligned sequences are available from the Systematic Biology Website (www. utexas.edu/ftp/depts/systbiol).

There is agreement among the different phylogenetic analyses for all well-supported nodes. The equally weighted (MP) analysis produced a single tree, 1586 steps long. The weighted-parsimony analysis (WP) produced a single tree 7231 steps long. Monophyly of Marmota is supported by $100 \%$ bootstraps in all analyses and a decay index of 19. Two major clades constitute Marmota. A western North American (Nearctic) clade is formed by caligata, flaviventris, olympus, and vancouverensis (node A; Fig. 5). This clade is well supported, with $100 \%$ ML bootstrap, and a decay index of 
TABLE 2. Extended

\begin{tabular}{cccccccccccccc}
\hline 12 & 13 & 14 & 15 & 16 & 17 & 18 & 19 & 20 & 21 & 22 & 23 & 24 & 25 \\
\hline 64 & 52 & 57 & 57 & 57 & 59 & 62 & 56 & 61 & 66 & 62 & 62 & 54 & 53 \\
133 & 121 & 113 & 113 & 113 & 112 & 118 & 110 & 112 & 121 & 118 & 119 & 129 & 128 \\
128 & 112 & 110 & 110 & 112 & 106 & 109 & 105 & 107 & 112 & 111 & 112 & 122 & 119 \\
122 & 121 & 111 & 110 & 114 & 105 & 111 & 109 & 112 & 123 & 123 & 123 & 128 & 125 \\
124 & 121 & 115 & 115 & 114 & 106 & 112 & 110 & 113 & 126 & 126 & 126 & 127 & 124 \\
110 & 111 & 92 & 92 & 98 & 100 & 107 & 96 & 98 & 103 & 107 & 107 & 120 & 119 \\
115 & 113 & 101 & 101 & 105 & 95 & 102 & 99 & 101 & 100 & 104 & 104 & 115 & 114 \\
108 & 110 & 98 & 98 & 102 & 100 & 109 & 100 & 102 & 97 & 105 & 105 & 116 & 115 \\
116 & 109 & 96 & 96 & 97 & 110 & 113 & 104 & 108 & 107 & 107 & 107 & 109 & 108 \\
115 & 109 & 97 & 97 & 98 & 109 & 114 & 105 & 109 & 108 & 108 & 108 & 110 & 109 \\
1 & 110 & 96 & 96 & 95 & 105 & 111 & 107 & 109 & 116 & 105 & 105 & 123 & 118 \\
0 & 111 & 97 & 97 & 96 & 106 & 112 & 108 & 110 & 117 & 106 & 106 & 124 & 119 \\
0.142 & 0 & 62 & 62 & 63 & 94 & 107 & 100 & 105 & 99 & 107 & 106 & 122 & 116 \\
0.117 & 0.066 & 0 & 0 & 23 & 92 & 99 & 94 & 96 & 94 & 91 & 91 & 107 & 105 \\
0.117 & 0.066 & 0 & 0 & 23 & 92 & 99 & 94 & 96 & 94 & 91 & 91 & 107 & 105 \\
0.116 & 0.068 & 0.022 & 0.022 & 0 & 94 & 102 & 101 & 103 & 94 & 93 & 93 & 110 & 110 \\
0.134 & 0.112 & 0.109 & 0.109 & 0.112 & 0 & 36 & 68 & 68 & 99 & 96 & 96 & 108 & 101 \\
0.145 & 0.134 & 0.120 & 0.120 & 0.125 & 0.035 & 0 & 67 & 69 & 99 & 98 & 98 & 107 & 98 \\
0.136 & 0.119 & 0.111 & 0.111 & 0.122 & 0.075 & 0.074 & 0 & 12 & 96 & 91 & 91 & 99 & 90 \\
0.141 & 0.129 & 0.116 & 0.116 & 0.126 & 0.076 & 0.078 & 0.011 & 0 & 101 & 94 & 94 & 100 & 91 \\
0.152 & 0.120 & 0.111 & 0.111 & 0.112 & 0.120 & 0.121 & 0.114 & 0.122 & 0 & 70 & 70 & 84 & 81 \\
0.133 & 0.133 & 0.107 & 0.107 & 0.110 & 0.114 & 0.117 & 0.106 & 0.112 & 0.076 & 0 & 0 & 85 & 84 \\
0.133 & 0.131 & 0.107 & 0.107 & 0.110 & 0.114 & 0.117 & 0.106 & 0.112 & 0.077 & 0 & 0 & 85 & 84 \\
0.162 & 0.156 & 0.131 & 0.131 & 0.136 & 0.134 & 0.133 & 0.117 & 0.120 & 0.097 & 0.097 & 0.097 & 0 & 23 \\
0.155 & 0.147 & 0.129 & 0.129 & 0.137 & 0.124 & 0.120 & 0.104 & 0.107 & 0.093 & 0.097 & 0.097 & 0.022 & 0 \\
\hline
\end{tabular}

10, which increases to 17 if olympus is excluded because of the smaller number of bases sequenced for olympus (577). The second major clade (node B) includes the remaining 10 species, with a high bootstrap of $95 \%$ but a decay index of only 1 . This high bootstrap but low decay index illustrates that these two indices measure different aspects of nodal support as well as the potential impact of refined evolutionary models. Bootstrap values for this node in the other analyses are $44 \%(\mathrm{MP}), 63 \%(\mathrm{NJ})$, and $89 \%$ (WP). The clade is unambiguously supported by two unique transversions at first and third positions (at positions 997 and 870; plus 12 homoplastic transitions) that receive weights of 1 in decay index calculations but have more influence on the more parameter-rich analyses.

Within this major clade (B), all analyses show very short basal branches and weak resolution. The MP and ML trees both place monax as sister to the remaining species, which are all Palearctic except for broweri. Support for this node (Palearctic species plus broweri) is weak, with only $36 \%$ ML bootstrap. The NJ tree places monax as sister to the sibirica-baibacina clade, whereas WP places it sister to marmota plus broweri. The European marmota appears to be a basal member of clade B, either as sister to all remaining clade B species (ML, NJ, MP) or as the sister species to broweri (WP), but again, none of the deeper nodes in clade B is well supported. The best supported clades in this group are the southwest Asian species pair caudata-menzbieri ( $100 \%$ bootstrap, decay index of 12), the central/western pair bobak-baibacina (95\% bootstrap, decay index of 6), and an eastern camtschatica group (95\% bootstrap, decay index of 6 ), which includes the probable species pair sibirica- 


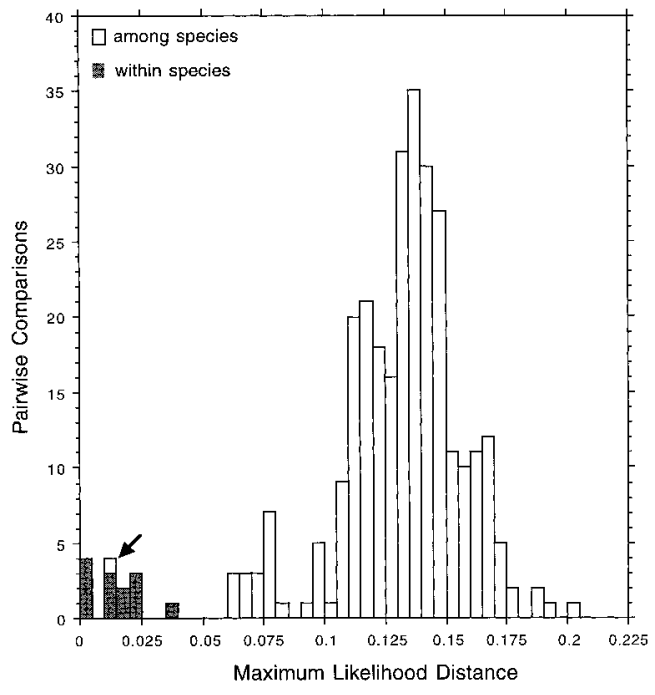

FIGURE 4. Histogram of maximum likelihood genetic distances, calculated using the same model (GTR $+\mathrm{I}+\Gamma)$ and parameters as in the ML phylogenetic analysis. The single interspecific distance $<5 \%$ (caligata/vancouverensis ) is indicated by the arrow.

himalayana $(75 \%$ bootstrap, decay index of 4). The bobak and camtschatica groups appear to be sister taxa with moderate support (78\% bootstrap, decay index of 4 ), and all the analyses except WP place the Alaskan broweri as sister to the caudata group (54\% ML bootstrap, decay index of 4).

Among the four western Nearctic species, the species pair of caligata and vancouverensis is well supported at $99 \%$ ML bootstrap and decay index of 10 . Other relationships are uncertain. ML and MP place olympus as the sister species to caligata plus vancouverensis, whereas $\mathrm{NJ}$ and $\mathrm{WP}$ place it one node lower. In all analyses, the branch leading to caligata/vancouverensis/ olympus or caligata/vancouverensis/flaviventris is short but receives moderate bootstrap support $(63-80 \%)$, given that there are effectively only three possible alternate placements.

\section{Hypothesis Testing}

Using the optimal trees from the MP and ML analyses, we performed KishinoHasegawa and Templeton tests on the a priori hypotheses presented in the Introduction and in Figure 2. These tests were evalu-

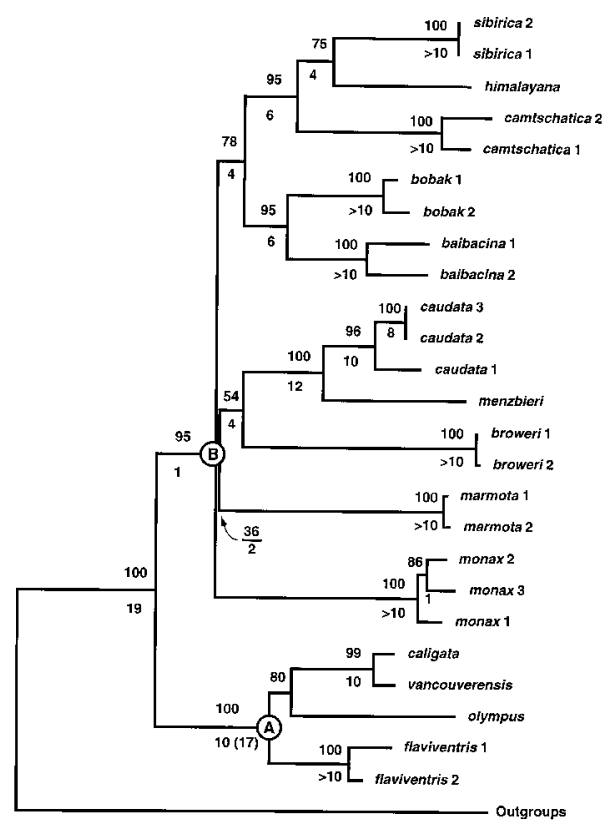

FIgURE 5. Maximum likelihood phylogram of Marmota obtained by using best-fitting model (GTR + I + $\Gamma)$ and parameters. ML bootstrap percentages are above the branches; decay indices calculated for the MP tree are below the branches. Outgroups are pruned for presentation.

ated in terms of the estimates of support for each node from the cyt $b$ data. Results are summarized in Table 3.

1. Marmota is not monophyletic.-Rejected. All analyses strongly support the monophyly of Marmota. Trees conforming to the alternative hypothesis are significantly longer (1605 steps, $P=0.008-0.02$ ) and less likely (8108 log-likelihood units, $P<0.0001$ ). With $100 \%$ bootstrap support and a decay index of 19, Marmota is the best supported supraspecific clade in the analysis.

2. M. broweri and M. camtschatica are sister species.-Rejected. The most thoroughly expounded presentation of this hypothesis was by Hoffmann et al. (1979). Most, but not all, equally most-parsimonious trees under this constraint were significantly worse, depending on the particular character distributions associated with the different topologies. Although some topologies consistent with this hypothesis cannot be rejected by all tests 
TABLE 3. Results of Kishino-Hasegawa (KH) and Templeton (T) tests for alternative hypotheses. Hypothesis numbers refer to those used in the text and Figure 2. MP and ML scores are for those optimal trees conforming to the a priori constraints. $P$-values are for the constrained trees, determined by using $\mathrm{KH}$ and T tests.

\begin{tabular}{llllll}
\hline Hypothesis & MP & \multicolumn{1}{c}{$P(\mathrm{KH}-\mathrm{MP})$} & \multicolumn{1}{c}{$P(\mathrm{~T}-\mathrm{MP})$} & ML & $P(\mathrm{KH}-\mathrm{ML})$ \\
\hline 1 & 1605 & $0.0077-0.009$ & $0.021-0.022$ & 8108 & $<0.0001$ \\
2 & 1601 & $0.011-0.051$ & $0.027-0.078$ & 8069 & 0.029 \\
$3 \mathrm{a}$ & 1641 & $<0.0001$ & $<0.0001$ & 8133 & $<0.0001$ \\
$3 \mathrm{~b}$ & 1621 & 0.0002 & 0.0006 & 8115 & $<0.0001$ \\
4 & 1596 & 0.13 & 0.17 & 8061 & 0.11 \\
5 & 1586 & na & na & 8046 & na \\
6 & 1588 & n.s. & n.s. & 8054 & n.s. \\
7 & 1602 & 0.0002 & 0.0009 & 8070 & 0.023 \\
8 & 1587 & n.s. & n.s. & 8055 & n.s. \\
\hline
\end{tabular}

${ }^{a}$ na $=$ not applicable, because test tree identical to optimal tree.

(i.e., $0.05<P<0.08$ for one of the tests), all constrained topologies are rejected by at least one test.

3. M. broweri and M. caligata are conspecific or sister species.-Rejected. Because the original proposals did not exclude the possibility that vancouverensis was as closely related to caligata as was broweri, we divided this hypothesis into two subhypotheses; the strict interpretation $3 a$ that broweri and caligata are most closely related, and the less restrictive interpretation $3 \mathrm{~b}$, which allows vancouverensis to be most closely related to one of the former species. Both alternatives are strongly rejected, and even the less restrictive alternative requires 35 extra steps $(P=0.0001-0.0002)$. We can be confident in excluding broweri from the caligata group sensu stricto, thus making the scenario of a return invasion of North America by broweri more plausible (see hypothesis 4).

4. Single crossing of Beringia.-Not rejected. This biogeographic scenario would suggest that a monophyletic group exists that encompasses all the Palearctic species and no others. Nearctic species could be either monophyletic or paraphyletic with respect to the Palearctic species. Yet, optimal trees in each analysis nested the Alaskan broweri within an otherwise Palearctic group, suggesting that it may be derived from a secondary dispersal across Beringia. However, the alternative hypothesis presented in Figure 2 is not significantly longer or less likely than the optimal trees $(P=$ 0.11-0.17). Thus, the possibility that broweri has retained an ancestral Beringian distribution and separated from the Palearctic clade by a single vicariance event cannot be rejected, and either single or multiple crossings of Beringia are consistent with current data.

5. Original diversification in North America.Not rejected. If the fossil evidence is correct and Marmota originated in North America, one might expect that the root of the tree would lie within North America, leaving the Nearctic species basal and paraphyletic with respect to the Palearctic species. That is precisely the pattern seen in the optimal trees, with monax more closely related to the Palearctic species (including broweri, node B, Fig. 5) than to the western Nearctic clade (node A). This indicates that North American diversification is the most likely scenario, given the data. However, two additional hypotheses can be evaluated; reciprocal monophyly of these two groups, which would be equivocal regarding the biogeographic scenario, and the Palearctic group being basal and paraphyletic, which would suggest an origination in the Palearctic. Trees conforming to these alternatives are five and three steps longer, respectively. These are not significant differences, and thus the statistical tests do not provide a basis for choosing among these scenarios.

6. Black-tipped hairs evolved once.-Not rejected. Assuming that black-tipped hairs 
evolved once with no reversals requires monophyly of all Palearctic species (plus broweri) to the exclusion of marmota. This involves moving marmota one node basally so that it is sister to the remaining Palearctic clade. Such trees are only two steps longer and are not significantly different. Therefore, the mitochondrial data are uninformative regarding this aspect of pelage evolution.

7. Increased sociality to large colonies evolved once.-Rejected. Assuming no reversal, this hypothesis implies that bobak, sibirica, and himalyana form a monophyletic group. All the optimal trees place $h i$ malyana and sibirica together, but bobak is always the sister species to baibacina. The shortest trees consistent with hypothesis 7 are 16 steps longer $(P=0.0002-0.0009)$ and differ by 24 log-likelihood units $(P=$ 0.023). Thus the possibility that this component of social evolution has been homoplastic has strong support. This homoplasy thus allows the examination of associations between the gain or loss of coloniality and other factors to which it might be an adaptation. If coloniality has been a unique case, no association could be assessed.

8. Minimum karyotypic evolution among Nearctic species, consistent with the transformation series $2 \mathrm{n}=38 \rightarrow 40 \rightarrow 42$. - Not rejected. Assuming no homoplasy, this transformation series predicts that olympus is the sister species to a clade formed by caligata, flaviventris, and vancouverensis. The ML and MP analyses nest olympus within this clade, whereas NJ and WP are consistent with the karyotypic hypothesis. MP and ML trees matching the prediction are only one step longer and slightly less likely, and thus hypothesis 8 can not be rejected. The mitochondrial data remain equivocal regarding the precise relationship of olympus, although it clearly belongs to a western Nearctic clade.

Thus, hypotheses 1 (Marmota not monophyletic), 3a (broweri sister to caligata), 3b (broweri sister to caligata/vancouverensis), and 7 (coloniality evolved once) can be rejected. Significance levels are marginal for

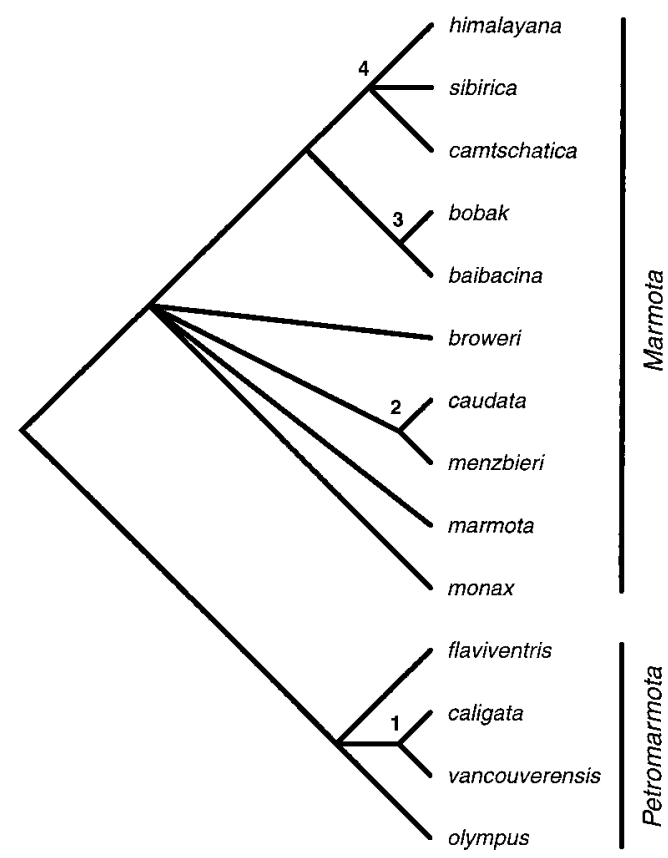

FIGURE 6. Summary topology incorporating clades with robust support that provides the basis of the classification presented in the text. $1=$ caligata group; $2=$ caudata group; 3 = bobak group; $4=$ camtschatica group.

hypothesis 2 (broweri sister to camtschatica), but hypotheses 4 (single crossing of Beringia), 5 (original diversification in North America), 6 (black-tipped hairs evolved once), and 8 (simple karyotypic transformation) cannot be rejected.

\section{DisCUSSION \\ Systematics}

Figure 6 summarizes those phylogenetic hypotheses about which we are confident. In accordance with those results, we propose the classification scheme in Table 4.

Petromarmota, subgen. nov., is defined as the most recent common ancestor of $M$. olympus, M. flaviventris, and M. caligata and all its descendants. This western North American clade is characterized by dorsal pelage with light-tipped guard hairs and a white nose and chin. A light patch is also present between or just in front of the eyes, separated from the white nose by a dark brown to black transverse stripe (Hoffmann et al., 1979). Basal members of the nominal subgenus, M. (Marmota) marmota and $M$. 
TABLE 4. Proposed classification of the genus Marmota.

Genus Marmota Blumenbach, 1779

Synonyms: Marmota Frisch, 1775; Glis Erxleben, 1777; Arctomys Schreber, 1780; Lagomys Storr, 1780; Lipura

Illiger, 1811; Marmotops Pocock, 1922

Subgenus Petromarmota Subgen. Nov.
flaviventris
caligata group
caligata
vancouverensis
olympus
Subgenus Marmota
monax
marmota
broweri
caudata group
caudata
menzbieri
bobak group
bobak
baibacina
camtschatica group
camtschatica
himalayana
sibirica

(M.) monax, also possess light-tipped dorsal guard hairs and a light-colored nose, but lack the contrasting light-and-dark pattern on the face seen in Petromarmota, most prominent in $M$. (P.) flaviventris and $M$. (P.) caligata. The facial pattern is present but subdued in $M$. $(P)$. olympus (more noticeable in subadults and juveniles), but is obliterated in the melanistic allospecies $M$. (P.) vancouverensis (Hoffmann et al., 1979). The etymology refers to the rocky habitat preference of the new subgenus's constituent species; type species, M. caligata.

The terminal clades of the subgenus Marmota, namely, the bobak and camtschatica groups, have a solid black cap from the tip of the nose backward, merging into the black-tipped dorsal guard hairs; their winter pelage is long and soft, in contrast to Petromarmota and the less derived species of subgenus Marmota. All species in this subgenus except $M$. broweri have yellowish to bright ochraceous fur covering the venter.

\section{Evolutionary History}

The most recent survey of the genus was that of Bibikov (1996). In his view, Marmota first appeared in the Central Asian mountains in the Pliocene, adapted to montane meadow and steppe habitats. However, he considers the oldest of the living species to be the North American marmots, plus marmota of Western Europe. North America and Asia were independent loci of speciation; in the former, monax became secondarily adapted to lowland forest and meadow, and in the latter, various species adapted to both xeric steppe and periglacial steppetundra and permafrost. Both caudata and menzbieri represent early Asian branches, whereas a baibacina-like ancestor gave rise to the modern bobak group, with its related taxa, himalayana, sibirica, and camtschatica. Thus, he believes that bobak and himalayana/ sibirica evolved into xeric steppe populations in parallel. Bibikov also suggests that broweri derived from the lineage represented by camtschatica and then colonized Alaska.

In contrast, the molecular data are consistent with the traditional view that the genus arose in North America. The oldest fossil of Marmota is now known to be from the middle Miocene of Nebraska (Clarendonian/Hemphilian) (Black, 1963; Savage and Russell, 1983), whereas the oldest Old World fossils are Pliocene to early Pleistocene (Bibikov, 1996; Savage and Russell, 1983). The oldest fossil of a modern species is assignable to monax from the mid-Pleistocene (Irvingtonian) in several sites in the southeastern USA, within the present range of the species (Kurten and Anderson, 1980). Giboulet et al. (1997) date the divergence of marmots from some ground squirrels at 6 million years ago (MYA), based on DNA hybridization evidence. However, given the evidence of Spermophilus paraphyly (Thomas and Martin, 1993), a different selection of Spermophilus more closely related to Marmota could have had their data support an even earlier divergence for Marmota. This again illustrates the importance of careful taxon sampling in applications of the molecular clock. Still, the estimated date is at odds with a revised North American paleontological time scale, which places the earliest species of Marmota, vetus, at 9.5 MYA (J. Alroy, pers. comm.).

Other modern species are not known until later in the Pleistocene. These records support Bibikov's argument that the New World species are, among the surviving Ho- 
larctic species, the older radiation, and this conclusion is supported by paraphyly of Nearctic species in our phylogenetic tree (Fig. 6). The tree does not support a close relationship between monax and marmota, as advocated by Hoffmann and Nadler (1968) and Bibikov (1996). Instead, the similarity between these taxa may be due to retention of plesiomorphic character states. The remaining species of M. (Marmota) form two large clades, one consisting of broweri, menzbieri, and caudata, and the other two species groups (bobak and camtschatica) that were placed in the bobak group by Bibikov and many earlier authors.

The major surprise in our analysis is the position of broweri within the tree. After its specific distinctness was recognized (Rausch and Rausch, 1965), most authors believed it to be closely allied with camtschatica, representing a late Pleistocene migration to Alaska from Siberia and subsequent speciation (Hoffmann and Nadler, 1968; Hoffmann et al., 1979; Bibikov, 1996). This hypothesis receives little support from our analyses. However, Rausch and Rausch (1971:96) stated: "From the evidence now available, we consider broweri to be probably a relict North American species which became established in the Brooks Range during pre-Wurm time, rather than a late Pleistocene invader of middle Asian derivation." If they meant that broweri was a member of a paraphyletic North American grade, possibly sister to a Palearctic group, then their hypothesis cannot be rejected. If however, they meant that broweri is a member of an exclusively North American clade (e.g., Petromarmota), then their hypothesis is rejected strongly by the cyt $b$ data (results not shown).

The long-tailed, or red marmot (caudata) and Menzbier's marmot (menzbieri) are the most divergent morphologically of all the members of the genus; the former is the largest, with the longest tail, and the latter is the smallest, with the shortest tail. Nevertheless, they form a monophyletic group with strong support from our data. Bibikov (1996) remarks that they share certain primitive features with the American marmots (rougher pelage and bright, contrasting color with light spots on sides of head and body), and earlier immunological and nu- cleotide sequence comparisons indicated that the two species were closer to each other than to species in the bobak or camtschatica groups (Baranov and Vorontsov, 1973; Zholnerovskaya et al., 1992; Lyapunova et al., 1995). Genetic distances between these two species (6.5-6.8\%) are similar to other closely related taxa: flaviventris and caligata/vancouverensis (6.3-7.2\%), baibacina and bobak (7.4-7.8\%), and himalayana and sibirica $(7.6 \%)$. Their montane Middle Asian distributions are contiguous and are the smallest ranges of any of the Asian marmots.

The other large clade comprises the bobak and camtschatica groups. The first consists of baibacina and bobak; the other includes the species himalayana, sibirica, and camtschatica. These species are allo- to parapatric in distribution across an enormous expanse of territory, from the Ukraine to Kamchatka in far northeastern Siberia, and share similar karyotypes $(2 n=38$; FN $=64-66)$ except for camtschatica $(2 n=40 ; \mathrm{FN}=62)$ (Lyapunova and Vorontsov, 1969; Vorontsov et al., 1969). These species exhibit different patterns of habitat adaptations. The most generalized in this respect is baibacina, which occupies montane steppe and meadow in the Altai (M. b. baibacina) and Tien Shan (M. b. centralis) mountains but is also found in foothill woodland in southern Siberia and in rolling hills of central Kazakhstan, where it is in contact with M. bobak shaganensis. Hybrids between the two species have been reported in this contact zone (Kapitonov, 1966; Sludskii, 1969), but specimens from Kizil-Rai and Karkaralinsk retain their morphological distinction, and there is no evidence of intergradation between the two species (Nikol'skii et al., 1983). M. bobak, the sister species to baibacina in our tree, is more specialized, is able to occupy xeric steppes, and forms large colonies; Bibikov (1996) regarded it as having diverged from the more generalized baibacina.

The camtschatica group consists of the species pair himalayana and sibirica, and camtschatica, which is more divergent in morphology, ecology, and karyology (Baranov and Vorontsov, 1973; Vorontsov and Lyapunova, 1984). All three of these species are adapted to life in the permafrost zone, as is the American broweri. The tarbagan 
(sibirica) is similar morphologically to baibacina, and there were early reports of intergradation between $M$. b. baibacina and M. s. caliginosus in the montane steppes of the western Mongolian Altai (Bannikov, 1954). However, Ziminia (1978) provided evidence of specific separation, and Smirin et al. (1985), analyzing the contact zone, found that the two taxa occupied distinct colonies and differed in vocalizations; Sokolov and Orlov (1980) also indicated sympatry in the contact zone, although limited hybridization is possible.

Both species occupy montane steppe habitats but differ in preferred biotopes. "In the areas of joint settlement the gray marmots $\{M$. b. baibacina $\}$ occupy wet meadow slopes and interfluvial areas ... while M. s. sibirica usually settle in the dry steppe valleys" (Bibikov, 1996:36). Like bobak, sibirica is adapted to more open, rolling landscapes and avoids steep, rocky terrain; because "the type of settlement is a steppe ..., the animals are distributed rather evenly ..." and larger colonies are formed than is the case with montane species (Bibikov, 1996:36).

The sister species to sibirica is himalayana, distributed widely on the Tibetan Plateau. Because it is quite similar morphologically to members of the bobak group, and its distribution is entirely allopatric relative to other species in the group, it has sometimes been considered a race of bobak. However, the genetic distances (Table 2) and tree topology show it is well separated from that species. Its habitat varies geographically; around the edges of the plateau, it is found in rocky montane biotopes similar to those frequented by baibacina and American montane marmots, but in areas of less rugged relief across the expanse of the plateau, it occupies the flat to rolling open surface of the alpine steppe and semidesert. There it occurs in large colonies (Jameson, 1847) similar to those formed by bobak and sibirica.

This pattern seems to indicate that the adaptation of marmot lineages to xeric open steppe habitats has occurred independently in several species, and that these adaptations relate to a number of facets of their biology, including seasonality, food habits, and social behavior. A similar paral- lelism can also be seen in the adaptations of camtschatica and broweri to the extremes of cold and short growing season in northeast Siberia and northern Alaska, respectively. As noted above, most previous authors have considered broweri to be the sister species to camtschatica - an Asian marmot that migrated into Alaska in the late Pleistocene-but as Rausch and Rausch (1971) postulated, the cyt $b$ tree suggests that its ancestry goes back at least to the beginning of the radiation of the Asian marmots (Zimina and Gerasimov, 1973).

Despite similarities of geography and Pleistocene history between the Olympic Peninsula and Vancouver Island (Hoffmann, 1981), the relationship of the two marmots endemic to these regions, olympus and vancouverensis, differ. The latter is very closely related to caligata, which occurs in the adjacent Coast Ranges of British Columbia as well as more widely in the northern Cascades and Rocky Mountains. The low genetic divergence of vancouverensis from caligata (1.2\%; Table 2, Fig. 5), suggests that it is recently isolated, but fixed differences not only in color and vocalizations but also habitat and behavior (Barash, 1989) indicate that it is an insular allospecies of the superspecies caligata (Hoffmann et al., 1979). In contrast, olympus may be a basal member of Petromarmota (Fig. 5); its genetic distance from caligata, vancouverensis, and flaviventris is greater-5.3-6.8\% (GTR distance, calculated only over the $577 \mathrm{nu}$ cleotides), about the same level as the species pairs bobak-baibacina $(5.8-7.0 \%)$ or himalayana-sibirica (6.1-6.4\%) for the same regions of the gene. The Olympic marmot may be a relict species that differentiated during isolation in an early- to mid-Pleistocene ice-free refugium (Hoffmann, 1981).

After the acceptance of this manuscript, a marmot phylogeny was published by Kruckenhauser et al. (1999). Their study included complete cyt $b$ sequences for 10 of the 14 species and yielded the same MP phylogeny as ours (after pruning the four species) with one exception. They found $M$. olympus to be most closely related to vancouverensis, in contrast to its basal position in Petromarmota in our analyses. The two olympus sequences are $9 \%$ divergent. When both data sets are analyzed together, their 
olympus and vancouverensis form a clade that is sister to our vancouverensis, whereas the remaining topology matches that reported here. We think it likely that at least one of the olympus samples was contaminated. The procedures we used to preclude and test for that possibility are discussed in Methods. Neither olympus sequence appears to be related to the pseudogenes discovered by Kruckenhauser et al. (1999), being $>14 \%$ divergent (absolute differences). The olympus and vancouverensis sequences from Kruckenhauser et al. (1999) differ at seven positions, four of which result in unique amino acid substitutions (among the 47 sequences) and three of those being between hydophobic and ambivalent amino acids. Despite the greater overall divergence seen between our olympus and other Petromarmota, only 5 of 34-37 differences are nonsynonymous, and only 2 of those are unique to olympus. Given that their olympus was a museum skin collected in 1950 and that they preferentially amplified a pseudogene, the pattern of nucleotide substitution is consistent with their sequence being a vancouverensis contaminant coupled with $0.6 \%$ sequencing error. The substitution pattern in our olympus sample is not consistent with the high error rate necessary to account for its basal phylogenetic position if it was contaminated.

We note that caligata, olympus, and vancouverensis are represented in our data set by single individuals, and unsampled intraspecific variation could influence this conclusion. However, none of the 13 intraspecific comparisons we have (Table 2, Fig. 4) show divergence $>3.5 \%$ (distance over entire gene), and all divergences $>1.1 \%$ involve different subspecies. It seems unlikely, therefore, that intraspecific variation in Petromarmota will prove to be great enough to affect the topology of relationships estimated from the data at hand.

A similar argument can be made regarding the robustness of the entire tree topology to the effect of lineage sorting, which can cause any particular gene tree to differ from the true species tree (Maddison, 1997). Pairwise intra- and interspecific divergence overlap only marginally (Fig. 4). Thus the available data indicate that many nodes in the phylogeny will be resistant to lineage- sorting effects. However, basal internodes in the subgenus Marmota (for which we claim no resolution) are within the bounds of intraspecific variation and possibly are subject to lineage-sorting (Moore, 1995); thus, even with additional mitochondrial sequence data, we should be cautious in assessing our confidence for any resulting resolution.

\section{CONCLUSIONS}

The cyt $b$ data and analyses are consistent with the following scenario. Marmota diverged from Spermophilus in North America and radiated into several lineages, although the data cannot reject an Asian origin. One lineage led to the subgenus Petromarmota, which is today found in the montane west. Petromarmota includes two species with highly restricted distributions: $M$. vancouverensis is endemic to Vancouver Island and is only recently derived from caligata; on the other hand, olympus, which is endemic to the Olympic Peninsula, is a basal member of the subgenus, and if karyotypic evolution has been simple in this group, may be the sister species to the remaining members. The other surviving lineage of Nearctic origin may have crossed Beringia into Asia not long after its divergence from Petromarmota, leaving monax (the woodchuck) in North America, and then spread across the Palearctic. Why this ancestral marmot crossed the Bering land bridge, whereas the Petromarmota lineage did not, may have been influenced by both geographic distribution and habitat differences. Judging from the habitat preferences of modern monax, its ancestral form probably occupied a larger array of habits and occurred closer to (perhaps within) Beringia. Ancestral Petromarmota may have been a more specialized montane form occupying a more southerly range in the western mountains and thus was less likely to cross Beringia into the Palearctic. Alternatively, a Petromarmota-like species did cross Beringia-a northerly sister-species to Petromarmota that subsequently evolved the derived monax - which was followed by the extinction of its Petromarmota-like descendant in the Nearctic. Perhaps broweri is that descendant that did not go extinct. A more definitive estimate of the plesiomorphic habitat 
preferences in Marmota would assist in choosing between these alternatives.

Differentiation into the major Palearctic lineages appears to have been rapid, judging from the short internal branches and poor phylogenetic resolution. Subsequent speciation in the three to five Palearctic lineages appears to have resulted in parapatric sister taxa. The optimal trees support the hypothesis that the Alaskan broweri represents a recrossing of Beringia from the east. However, the data cannot reject the possibility that broweri may, like monax, be a remnant of the earlier Nearctic phase of the M. (Marmota) radiation prior to the Palearctic invasion. The data are sufficient to demonstrate that broweri is not sister to camtschatica nor a member of Petromarmota, as had been the preferred hypotheses.

We have used the molecular phylogeny to examine one important aspect of marmot biology, the evolution of increased sociality and large colony formation. A single origination of this trait without reversal can be rejected. A parsimony optimization of increased sociality on the optimal tree indicates that it has been gained (or lost) twice, and possibly three times, because olympus forms moderately large colonies. These multiple cases of social evolution will allow statistical tests of explicit ethological hypotheses, such as those proposed by Barash (1989) and Armitage (1999). Another likely example of convergence is between the camtschatica group and broweri for morphological traits associated with life in the permafrost.

Taking into account the evidence presented above and in Figure 5 regarding individual nodes on the tree, Figure 6 represents the summary topology for which we feel these data provide robust support and is the graphical representation of our taxonomy. Eight of 13 possible nodes are resolved, which represents a significant increase over the perhaps single node, Marmota, that could be considered well resolved by the sum of previous systematic studies. Although all nodes and hypotheses should be subject to further testing, resources should be concentrated on resolving those nodes that remain unresolved on this summary. The explicit statistical framework within which this analysis was con- ducted has as a benefit the ability to identify those hypotheses consistent with the data as well as rejecting inconsistent hypotheses. By doing so, this approach can more sharply focus the direction of subsequent investigations and streamline our efforts, given finite resources and time. A particular focus of future research should be the relationships among the major lineages of the nominate subgenus.

\section{ACKNOWLEDGMENTS}

We thank R. Harrison, J. Mercer, V. L. Roth, R. Thorington, R. Page, M. Wilkinson, and an anonymous reviewer for their suggestions and constructive critique of earlier drafts of the manuscript. Field research was supported by the Institute of Developmental Biology, Russian Academy of Sciences, Moscow; the Northwest Plateau Institute of Biology, Chinese Academy of Sciences, Xining; and by the Division of Mammals, National Museum of Natural History, Smithsonian Institution, Washington, D.C. We thank Drs. W. Arnold and Thomas Ruff of Phillips-Universität, Marburg; J. Cook of the University of Alaska, Fairbanks; P. Tongiori of the Department of Animal Biology, University of Modena, Italy; and D. Hafner of the New Mexico Museum of Natural History for loans of frozen tissue. We also thank A. Bryant of the Vancouver Island Marmot recovery team for supplying blood samples and Dr. Richard W. Thorington, Jr., Curator in Charge, for permission to obtain dry tissue from a specimen of $M$. olympus in the USNM collection. W. Kelley Thomas of the University of Missouri, Kansas City, kindly provided several primers and electronic copies of their published sequences. Collecting in Eurasia was funded in part from NSF grant DEB-9221504 to Drs. Richard Harrison and Paul Sherman, Cornell University (R. S. Hoffmann and E. Yensen, Co-Investigators). Laboratory work was supported by the Laboratory of Molecular Systematics, Smithsonian Institution and by a Scholarly Studies Grant from the Office of Fellowships and Grants, Smithsonian Institution.

\section{REFERENCES}

Anderson, S., A. T. Bankier, B. G. Barrell, M. H. L. DeBruijn, A. R. Coulson, J. Drouin, I. C. Eperon, D. P. Nierlich, B. A. Roe, F. SANger, P. H. Schreier, A. J. H. Smith, R. Staden, and I. G. Young. 1981. Sequence and organization of the human mitochondrial genome. Nature 290:457-465.

Armitage, K. B. 1975. Social behavior and population dynamics of marmots. Oikos 26:341-354.

Armitage, K. B. 1987. Social dynamics of mammals: Reproductive success, kinship and individual fitness. Train. Evol. 2:279-284.

Armitage, K. B. 1999. Evolution of sociality in marmots. J. Mammal. 80:1-10.

ARNOLD, W. 1990. The evolution of marmot sociality: II. Cost and benefits of joint hibernation. Behav. Ecol. Sociobiol. 27:239-246. 
Bannikov, A. G. 1954. Mlekopitayushchie Mongol'skoi Narodnoi Respublik \{Mammals of the Mongolian People's Republic\}. Academy of Sciences of the USSR, Moscow.

Baranov, O. K., AND N. N. Vorontsov. 1973. Serologicheskaya differentsiyatsiya pyati Palearkticheskikh vidov Marmota (Rodentia, Sciuridae) \{Serological differentiation of five species of Marmota (Rodentia, Sciuridae)\}. Zool. Zh. 52:577-583.

BARASH, D. P. 1989. Marmots. Social behavior and ecology. Stanford Univ. Press, Palo Alto, California.

BiвıKov, D. I. 1996. Die Murmeltiere der Welt. Spektrum Akademischer Verlag, Heidelberg.

BLACK, C. C. 1963. A review of the North American Tertiary Sciuridae. Bull. Mus. Comp. Zool. 130:109248.

Blumstein, D. T., J. Steinmetz, K. B. Armitage, and J. C. DANIEL. 1997. Alarm calling in yellow-bellied marmots: II. The importance of direct fitness. Anim. Behav. 53:173-184.

BREMER, K. 1994. Branch support and tree stability. Cladistics 10:295-304.

Ellerman, J. R., AND T. C. S. Morrison-Scott. 1951. Checklist of Palaearctic and Indian mammals 1758-1946. British Museum (Natural History), London.

Felsenstein, J. 1985. Confidence limits on phylogenies: An approach using the bootstrap. Evolution 39:783-791.

Fratti, F., C. Simon, J. Sullivan, and D. L. Swofford. 1997. Evolution of the mitochondrial cytochrome oxidase II gene in Collembola. J. Mol. Evol. 44:145-158.

Giboulet, O., P. Chevret, R. Ramousse, and F. CAtzeFLIS. 1997. DNA-DNA hybridization evidence for the recent origin of marmots and ground squirrels (Rodentia: Sciuridae). J. Mammal. Evol. 4:271-284.

Gromov, I. M., D. I. BibiKov, N. I. KalabuKov, AND M. N. MeIER. 1965. Fauna SSSR. Mlekopitayushchie, Volume 3, no. 2. Nazemnye Belich'i (Marmotinae) \{Fauna of the USSR. Mammals, Volume 3, no. 2. Ground Squirrels (Marmotinae)\}. Nauka, Moscow.

HAFNER, D. J. 1984. Evolutionary relationships of the Nearctic Sciuridae. Pages 3-23 in The biology of ground-dwelling ground squirrels (J. O. Murie and G. R. Michener, eds.). Univ Nebraska Press, Lincoln.

Hall, E. R. 1981. The mammals of North America, 2nd ed. John Wiley and Sons, New York.

Hall, E. R., AND K. R. KELSON. 1959. The mammals of North America. Ronald Press, New York.

Hasegawa, M., M. Kishino, and T. Yano. 1985. Dating the human-ape split by a molecular clock of mitochondrial DNA. J. Mol. Evol. 22:160-174.

HoffmanN, R. S. 1981. Different voles for different holes: Environmental restrictions on refugial survival of mammals. Pages 25-45 in Evolution today: proceedings of the Second International Congress of Systematic and Evolutionary Biology (G. G. E. Scudder and J. L. Reveal, eds.). Carnegie-Mellon University, Pittsburgh, Pennsylvania.

HofFMANN, R. S. 1984. An ecological and zoogeographical analysis of animal migration across the Bering land bridge in the Cenozoic. Pages 464-481 in Beringia in the Cenozoic (V. L. Kontrimavichus, ed.). Amerind, New Delhi, India.

HofFMANN, R. S., C. G. ANDERSON, R. W. J. Thorington, and L. R. Heaney. 1993. Family Sciuridae. Pages
419-465 in Mammal species of the world (D. E. Wilson and D. M. Reeder, eds.). Smithsonian Institution Press, Washington, D.C.

Hoffmann, R. S., J. W. Koeppl, and C. F. Nadler. 1979. The relationships of the amphiberingian marmots (Mammalia: Sciuridae). Occas. Pap. Mus. Nat. Hist. Univ. Kansas 83:1-56.

Hoffmann, R. S., And C. F. Nadler. 1968. Chromosomes and systematics of some North American species of the genus Marmota (Rodentia: Sciuridae). Experientia 24:740-742.

Hopkins, D. M., J. V. Matthews, JR., C. E. Schweger, S. B. Young, AND V. Stanley. 1982. Paleoecology of Beringia. Academic Press, New York.

Howell, A. H. 1915. Revision of the American marmots. North Am. Fauna 37:1-80.

Huelsenbeck, J. P., And B. Rannala. 1997. Phylogenetic methods come of age: Testing hypotheses in an evolutionary context. Science 276:227-232.

Huxley, J. S. 1940. The new systematics. Oxford Univ. Press, London.

Irwin, D. M., T. D. Kocher, AND A. C. Wilson. 1991. Evolution of the cytochrome $b$ gene of mammals. J. Mol. Evol. 32:128-144.

JAMESON, W. 1847. Extract of a letter. Calcutta J. Nat. Hist. 7:360-363.

Jukes, T. H., AND C. R. CANTOR. 1969. Evolution of protein molecules. Pages 21-132 in Mammalian protein metabolism (H. N. Munro, ed.). Academic Press, New York.

KAPITONOV, V. I. 1966. Rasprostranenie surkov v Tsentralnom Kazakhstane i perspectivy ikh promysla \{Distribution of marmots in Central Kazakhstan and perspective on their exploitation\}. Tr. Zool. Inst. (Alma-Ata) 26:94-134.

KIMURA, M. 1980. A simple model for estimating evolutionary rates of base substitutions through comparative studies of nucleotide sequences. J. Mol. Evol. 16:111-120.

Kishino, H., AND M. Hasegawa. 1989. Evaluation of the maximum likelihood estimate of the evolutionary tree topologies from DNA data, and the branching order in Hominoidea. J. Mol. Evol. 29:170-179.

Kruckenhauser, L., W. Pinsker, E. Haring, and W. ARNOLD. 1999. Marmot phylogeny revisited: Molecular evidence for a diphyletic origin of sociality. J. Zool. Syst. Evol. Res. 37:49-56.

Kurten, B., AND E. Anderson. 1980. Pleistocene mammals of North America. Columbia Univ. Press, New York.

Lyapunova, E. A., G. G. Boyeskorov, and N. N. Vorontsov. 1992. Marmota camtschatica Pall._Nearctic element in Palearctic Marmota fauna. Proc. Int. Symp. Alpine Marmot 1:185-191.

Lyapunova, E., M. Braun, D. Albright, M. AkhverDiAN, R. HOFFMAN, AND N. Vorontsov. 1995. Phylogeny of the Holarctic genus Marmota based on the studies of chromosomes and nucleotide sequences. Chrono. Res. 3:79.

Lyapunova, E. A., AND N. N. Vorontsov. 1969. Novye dannye o khromosomakh Evraziiskikh surkov (Marmota, Marmotinae, Sciuridae, Rodentia) (New data on chromosomes of Eurasian marmots ... \}. Pages 36-40 in Mlekopitayushchie \{Mammals. Evolution, karyology, faunistics, systematics\} (N. N. Vorontsov, ed.). Acad. Sci., Siberian Dept., Novosibirsk, Russia. 
Maddison, W. P. 1997. Gene trees in species trees. Syst. Biol. 46:523-536.

Moore, W. S. 1995. Inferring phylogenies from mtDNA variation: Mitochondrial-gene trees versus nuclear-gene trees. Evolution 49:718-726.

NiKOL'SKII, A. A., I. Y. YANINA, M. V. RUTOVSKAYA, AND N. A. Formozov. 1983. Izmenchivost' zvukova signala stepnovo i serovo surkovl (Marmota bobac, M. baibacina; Sciuridae, Rodentia) v zone vtorichnovo kontakta \{Variation in sound signals of steppe and gray marmots (Marmota bobac, M. baibacina; Sciuridae, Rodentia) in a zone of secondary contact\}. Zool. Zh. 62:1258-1266.

OGNEV, S. I. 1947. Zveri SSSR i prilezhashchikh stran \{Mammals of the USSR and adjacent countries\}, Volume 5. Gryzuny \{Rodents\}. Academy of Sciences of the USSR, Moscow.

RAUSCH, R. L. 1953. On the status of some arctic mammals. Arctic 6:91-148.

Rausch, R. L., AND V. R. Rausch. 1965. Cytogenetic evidence for the specific distinction of an Alaskan marmot, Marmota broweri Hall and Gilmore (Mammalia: Sciuridae). Chromosoma 16:618-623.

RAUSCH, R. L., AND V. R. RAusCH. 1971. The somatic chromosomes of some North American marmots (Sciuridae), with remarks on the relationships of Marmota broweri Hall and Gilmore. Mammalia 35:85-101.

SAMBROOK, E., F. Fritsch, AND T. Maniatis. 1989. Molecular cloning. Cold Spring Harbor Laboratory Press, Cold Spring Harbor, New York.

Savage, D. E., AND D. E. Russell. 1983. Mammalian paleofaunas of the world. Addison-Wesley, Reading, Massachusetts.

SLUDSKII, A. A. 1969. Mlekopitayushchikh Kazakhstana \{Mammals of Kazakhstan\}, Volume 1. Gryzuny (Surki i susliki) \{Rodents (Marmots and ground squirrels) $\}$. Nauka, Alma-Ata.

SMIRIN, Y. M., N. A. Formozov, D. I. BibIKOV, AND D. MyagmarzhaV. 1985. Kharakteristika poselenii dvukh vidov surkov (Marmots, Rodentia, Sciuridae) v zone ikh Kontakta na Mongol'skom Altae (Characteristics of settlement in two species of marmots (Marmots, Rodentia, Sciuridae) in their contact zone in the Mongolian Altai\}. Zool. Zh. 64:1873-1885.

SOKOlOV, V. E., AND V. N. Orlov. 1980. Opredelitel' mlekopitayushchikh Mongol'skoi Narodnoi Re- spubliki \{Guide to the mammals of the Mongolian People's Republic\}. Nauka, Moscow.

Templeton, A. 1987. Nonparametric inference from restriction cleavage sites. Mol. Biol. Evol. 4:315-319.

Thomas, W. K., AND S. L. Martin. 1993. A recent origin of marmots. Mol. Phylogenet. Evol. 2:330-336.

Vorontsov, N. N., AND E. A. Lyapunova. 1970. Khromosomnie chisla i vidoobrazovanie $\mathrm{u}$ nazemnikh belich'ikh (Sciuridae, Xerinae et Marmotinae) Golarktiki \{Chromosome numbers and species formation in ground squirrels (Sciuridae, Xerinae et Marmotinae) of the Holarctic\}. Byull. Mosk. Ova Ispyt. Prir. Otd. Biol. 75:112-126.

Vorontsov, N. N., And E. A. Lyapunova. 1984. Genetics and problems of trans-Beringian connections of Holarctic mammals. Pages 441-463 in Beringia in the Cenozoic era (V. L. Kontrimavichus, ed.) Oxonian Press, New Delhi, India.

Vorontsov, N. N., E. A. Lyapunova, AND N. G. ZAGORUIKO. 1969. Sravnitel'naya kariologiya i' stanovlenie izoliruyuschikh v rode Marmota \{Comparative karyology and the development of isolating mechanisms in the genus Marmota\}. Zool. Zh. 48:317-333.

YANG, Z. 1994. Maximum likelihood phylogenetic estimation from DNA sequences with variable rates over sites: Approximate methods. J. Mol. Evol. 39:306-314.

YANG, Z., N. GOLdMAN, AND A. FrIdAy. 1995. Maximum likelihood trees from DNA sequences: A peculiar statistical problem. Syst. Biol. 44:384-399.

Zholnerovskaya, E. I., D. I. Bibikov, And V. I. ERMoLAEV. 1992. Immunogenetical analysis of systematical relations among marmots. Proc. Int. Symp. Alpine Marmot 193-196.

ZiminA, R. P. 1978. Surki. Rasprostranenie i ecologiya \{Marmots. Distribution and ecology\}. Nauka, Moscow.

ZiminA, R. P., AND I. P. Gerasimov. 1973. The periglacial expansion of marmots. (Marmota) in middle Europe during the late Pleistocene. J. Mammal. 54:327-340.

Received 13 August 1998; accepted 12 January 1999 Associate Editor: R. Page 


\section{APPENDIX}

List of Marmota specimens sequenced; specimen IDs are as in the tables and figure. Abbreviations: AF $=$ University of Alaska, Fairbanks; ASU = Appalachian State University; IDB = Institute of Developmental Biology, Moscow; LMS = Laboratory of Molecular Systematics, Smithsonian Institution; NMMNH = New Mexico Museum of Natural History; NPIB = Northwest Plateau Institute of Biology, Xining, China; USNM = National Museum of Natural History. Tissues collected by J. F. Jacobs (JFJ) and R. S. Hoffmann (RSH) are housed in the collections of the Smithsonian Institution.

baibacina 1. baibacina kastschenkoi. Russia, Novosibirsk obl., vic. Novosibirsk; $55^{\circ} \mathrm{N}, 83^{\circ} \mathrm{E}$. IDB 23766.

baibacina 2. baibacina centralis. Kazakhstan, Chimkentsk obl., Bol'shoi Kokpak valley; $41^{\circ} 45^{\prime} \mathrm{N}, 69^{\circ} 30^{\prime} \mathrm{E}$. IDB 23929.

bobak 1. bobak bobak. Ukraine, Khar'kovsk obl., Velikii, Byrluksk rai.; 50N, 37²0'E. IDB 23765.

bobak 2. bobak bobak. Ukraine, Khar'kovsk obl., Velikii, Byrluksk rai.; 50N, 37²0'E. IDB 23803.

broweri 1. broweri. USA, Alaska, Brooks Range, vic. Anaktuvuk Pass; $68^{\circ} 10^{\prime} \mathrm{N}, 152^{\circ} \mathrm{W}$. USNM 583154, AF 7212.

broweri 2. broweri. USA, Alaska, Brooks Range, vic. Anaktuvuk Pass; $68^{\circ} 10^{\prime} \mathrm{N}, 152^{\circ} \mathrm{W}$. USNM 583155, JFJ 974.

caligata. caligata caligata. USA, Alaska, vic. Fairbanks; $65^{\circ} \mathrm{N}, 145^{\circ} \mathrm{W}$. AF 2384.

camtschatica 1. camtschatica camtschatica. Russia, Kamchatsk obl., Nilkovski rai.; 53ํN, 157³0’E. IDB 23764.

camtschatica 2. camtschatica doppelmayri. Russia, Buryatiya, Severo-Baikalsk rai., upper Chai River; $55^{\circ} 30^{\prime} \mathrm{N}$, $109^{\circ}$ E. IDB 23901.

caudata 1. caudata caudata. Pakistan, Northern Terr., Hunza, vic. Khunjerab Pass; $36^{\circ} 50^{\prime} \mathrm{N}, 75^{\circ} 20^{\prime} \mathrm{E}$.

caudata 2. caudata aurea. Kazakhstan, Dzhambulsk obl., Nerke; $43^{\circ} \mathrm{N}, 71^{\circ} 30^{\prime} \mathrm{E}$. IDB 23767.

caudata 3. caudata aurea. Kazakhstan, Dzhambulsk obl., Nerke; $43^{\circ} \mathrm{N}, 71^{\circ} 30^{\prime} \mathrm{E}$. IDB 23708.

flaviventris 1. flaviventris luteola. USA, Colorado, Gunnison Co., $\sim 7 \mathrm{mi}$. N of Crested Butte, along East River; $38^{\circ} 53^{\prime} \mathrm{N}, 106^{\circ} 58^{\prime} \mathrm{W}$. USNM 575170, JFJ 816.

flaviventris 2. flaviventris obscura. USA, New Mexico, Taos Co., Sangre De Cristo Mountains, N of Santa Fe; $36^{\circ} 30^{\prime} \mathrm{N}, 105^{\circ} 30^{\prime} \mathrm{W}$. NMMNH 128.

himalayana. himalayana robusta. China, Qinghai Prov., Yushu Aut. Pref., Nangqen Co., Bei-zha Forestry Sta., Ba Qu (river); $31^{\circ} 45^{\prime} \mathrm{N}, 96^{\circ} 30^{\prime} \mathrm{E}$. RSH 4478.

marmota 1. marmota marmota. Switzerland, Canton Grisons, Davos. 46 $47^{\prime} \mathrm{N}, 9^{\circ} 50^{\prime} \mathrm{E}$. LMS M00017.

marmota 2. marmota marmota. Italy, Modena, Monte Cimone. $44^{\circ} 12^{\prime} \mathrm{N}, 10^{\circ} 42^{\prime} \mathrm{E}$. LMS M00018.

menzbieri. menzbieri zachidovi. Uzbekistan, Tashkentsk obl., Chatkalsk zapovednik, vic. Parkent; $41^{\circ} 15^{\prime} \mathrm{N}, 70^{\circ} \mathrm{E}$.

IDB 23863.

monax 1. monax ochracea. Canada, Yukon, Ethel Lake; $63^{\circ} 21^{\prime} \mathrm{N}, 136^{\circ} \mathrm{W}$. Univ. RSH 4249

monax 2. monax rufescens. USA, New York, Tompkins Co., vic. Ithaca; $42^{\circ} 30^{\prime} \mathrm{N}, 76^{\circ} 30^{\prime} \mathrm{W}$. JFJ 947.

monax 3. monax monax. USA, North Carolina, no exact locality. $35^{\circ} 30^{\prime} \mathrm{N}, 82^{\circ} 30^{\prime} \mathrm{W}$. ASU 16756.

olympus. olympus. USA, Washington, Quinault River; $49^{\circ} 30^{\prime} \mathrm{N}, 125^{\circ} \mathrm{W}$. USNM 241947.

sibirica 1. sibirica sibirica. Russia, Chitinsk Obl. Ononsk rai., Pobeda; $57^{\circ} 30^{\prime} \mathrm{N}, 116^{\circ} \mathrm{E}$. IDB 9324.

sibirica 2. sibirica caliginosus. Russia, Buryatiya, Selenginsk rai., Toion, Gusinoe Lake; 51 N, 106 $15^{\prime}$ E. IDB 23906.

vancouverensis. vancouverensis. Canada, British Columbia, Vancouver Island, no exact locality. $49^{\circ} 30^{\prime} \mathrm{N}, 123^{\circ} 30^{\prime} \mathrm{W}$,

blood sample collection number 989244 . 